\title{
BMJ Open A cross-sectional study of factors associated with uptake of vaccination against influenza among older residents in the postpandemic season in Beijing, China
}

\author{
Yang Zheng, ${ }^{1}$ Peng Yang, ${ }^{1}$ Shuangsheng Wu, ${ }^{1}$ Chunna Ma, ${ }^{1}$ Holly Seale, ${ }^{2}$ \\ C Raina Maclntyre, ${ }^{2}$ Quanyi Wang ${ }^{1}$
}

To cite: Zheng $Y$, Yang $P$, Wu S, et al. A cross-sectional study of factors associated with uptake of vaccination against influenza among older residents in the postpandemic season in Beijing, China. BMJ Open 2013:3:e003662. doi:10.1136/bmjopen-2013003662

- Prepublication history for this paper is available online. To view these files please visit the journal online (http://dx.doi.org/10.1136/ bmjopen-2013-003662).

Received 12 August 2013 Revised 15 October 2013 Accepted 16 October 2013

CrossMark

\begin{abstract}
${ }^{1}$ Institute for Infectious Disease and Endemic Disease Control, Beijing Center for Disease Prevention and Control (CDC), Beijing, China ${ }^{2}$ School of Public Health and Community Medicine, UNSW Medicine, the University of New South Wales, Sydney, Australia
\end{abstract}

Correspondence to Dr Quanyi Wang; bjcdcxm@126.com

\section{ABSTRACT}

Objective: Annually, influenza epidemics are associated with high mortality rates, notably among elderly persons. The aim of the study was to examine the level of influenza vaccine coverage among Chinese residents aged 60 years and older and to examine the demographic, behavioural and lifestyle health factors associated with vaccine receipt.

Design: Cross-sectional study.

Setting: Beijing, China.

Participants: Stratified sampling was used to recruit participants for this study. A total of 2578 people aged 60 years and older consented to participate in this study. Questionnaires from 2481 participants were valid and were included in the final analysis.

Outcome measures: Influenza vaccination status and factors associated with vaccination.

Methods: In late 2010, a survey was conducted with residents from three urban and three rural districts in Beijing, China. Multivariate logistic regression was performed to detect the factors associated with influenza vaccination.

Results: 2481 older people (aged $\geq 60$ years) were included in the final analysis. In 2010, 44\% had received the annual influenza vaccine. Lower education level, poor health status of the participant, regular taking exercises and considering that vaccine is the best measure for preventing influenza were associated with influenza vaccination coverage.

Conclusions: Influenza vaccine coverage in Beijing still remains suboptimal. Further work needs to be undertaken to ascertain whether the methods used to distribute the vaccine are adequate and whether health professionals are appropriately promoting the vaccine.

\section{INTRODUCTION}

Influenza is a highly infectious viral disease that mainly attacks the upper respiratory tract. Both seasonal influenza and pandemic (H1N1) 2009 influenza may lead to severe

\section{Strengths and limitations of this study}

- This is the first study of its kind to examine factors associated with influenza vaccine uptake among older Chinese residents.

- The approach to recruitment and the extremely high response rate are the major strengths of this study.

- Unlike other studies, the influenza vaccination rates for three consecutive seasons were reported.

- One of the main limitations of the work is that vaccination receipt was based on self-report. Participants were asked about their vaccine history over a 3-year period, which probably would have resulted in recall bias, and vaccination status was not verified.

- The questionnaire used in this investigation did not capture all factors that are known to influence vaccine uptake (eg, religious beliefs, socioeconomic factors, etc).

complications from underlying diseases, primary viral or secondary bacterial pneumonia and death. Elderly individuals and especially those suffering from chronic medical conditions or immunological disorders account for approximately $90 \%$ of all influenza-related death. ${ }^{1}$ In Spain, the rate of death and the case-mortality rate were $8 / 100000$ population and $5.6 \%$, respectively, based on the national surveillance data for a 4-year period (1999-2002)..$^{2}$ Nearly 40 deaths $/ 100000$ person-years (representing around $3.2 \%$ of total deaths) are attributable to pneumonia and influenza in China according to the data of a large cohort study. ${ }^{3}$

Vaccination is considered to be the most effective way to decrease the morbidity and mortality associated with influenza virus 
infection. ${ }^{4}$ WHO recommends that prioritisation for influenza vaccination is given to elderly individuals compared with healthy younger adults. Currently, vaccination coverage rates of the elderly range widely among different countries. In the USA, the rate in 2009 was $68.9 \%$ among adults aged 65 years and older. ${ }^{5}$ In a crosssectional survey of 22 European countries, influenza vaccine coverage varied from $1.8 \%$ to $82.1 \%,{ }^{6}$ while in Canada it was documented as $55.2 \%{ }^{7}$ Finally, Lau et $a l^{8}$ found that only $31.1 \%$ of the surveyed older Chinese people in Hong Kong had received the influenza vaccination.

Previous studies have identified a number of factors associated with low vaccine receipt in this population including not being knowledgeable about the efficacy, side effects and duration of effectiveness with respect to influenza vaccination. ${ }^{8-10}$ Financial consideration was also an obstacle for vaccination among some elderly individuals. ${ }^{8}$ In comparison, Kwong et $a l^{10}$ found that social pressure such as a recommendation from a family member played an important role in motivating the elderly Chinese in Hong Kong to receive the influenza vaccine.

In Beijing, influenza vaccination is provided free of charge to all community-dwelling Beijing citizens aged 60 or over. As per the government policy, the vaccine is provided for free from October to December every year via the community hospitals. Until now, there have not been any studies that have examined the uptake of the influenza vaccine among older Beijing residents. Therefore, this study aimed to measure the coverage rate among residents aged $\geq 60$ years for seasons 2008/2009 to 2010/ 2011 in Beijing, China and the factors associated with vaccine receipt in the first postpandemic season.

\section{METHODS}

Subjects

Stratified sampling was used to recruit participants for this study. Three urban districts and three rural districts were randomly selected out of the total of 18 districts in Beijing. For the urban areas, suburbs in each district were ranked by population size, and five suburbs were randomly selected for each district. Then five streets were randomly chosen from each suburb, and 17 households were picked randomly according to their street number. For the rural areas, small towns in each district were ranked by population size, and five towns were randomly chosen for each district. Then five villages were randomly chosen from each town, and finally 17 households from the government's registry were selected randomly. All participants recruited were residents of the six districts who were aged 60 years and older who provided informed written consent

\section{Survey design and data collection}

Data collection was conducted between December 2010 and January 2011, via a face-to-face interview, using a standardised questionnaire. The following information was collected from participants: (1) demographic variables (gender, age, level of education, receipt of influenza vaccine); (2) perceived health status (presence of any chronic health conditions); (3) frequency of doing exercise of $30 \mathrm{~min}$ or more: regularly (once within 1 week) or rarely (less than $1 /$ week); (4) history of influenza-like illness (defined as fever (temperature, $\geq 38^{\circ} \mathrm{C}$ ) and cough or sore throat, with no other confirmed diagnosis) during 2010; (5) level of awareness about seasonal influenza (ie, what are the common influenza symptoms and when does influenza peak in Beijing?) and (6) attitudes towards methods of preventing influenza acquisition (ie, vaccination, ventilation, exercise and traditional Chinese medicine). Data were checked to ensure quality, completeness and validity by trained staff from Beijing CDC. Participants were excluded if there were any missing data in the survey.

\section{Statistical analyses}

The questionnaire data were entered in duplicate and verified using EpiData software V.3.1. The statistical analysis was undertaken using SPSS (V.16.0, SPSS Inc, Chicago, Illinois, USA). Descriptive analyses were performed to generate frequency distributions of the survey variables. Median and range values were calculated for continuous variables. Bivariate and multivariate logistic regression analyses were conducted to determine factors associated with vaccination against influenza. Matched ORs and $95 \%$ CIs were calculated. Variables with $\mathrm{p}<0.05$ in bivariate analysis were included in multivariate analysis. Collinearity was evaluated for all variables in the final model. Backward logistic regression was conducted by removing variables with $\mathrm{p}>0.10$, and statistical significance was defined as $\mathrm{p}<0.05$. For all analyses, probabilities were two-tailed and a $\mathrm{p}$ value of $<0.05$ was considered statistically significant.

\section{RESULTS}

A total of 2578 residents aged 60 years and older consented to participate in the study. Questionnaires from 2481 participants were valid, and $97(3.8 \%)$ had missing data. The age range of the valid participants was 60 99 years (median 65 years). Of the 1200 (48.4\%) participants who were men, only $317(12.8 \%)$ reported having a higher educational level (above senior middle school).

The influenza vaccination rates were $41.9 \%, 49 \%$ and 44.\% for seasons 2008/2009, 2009/2010 and 2010/2011, respectively. For all three seasons, the vaccination rate was higher for residents in rural areas, but there was no significant difference between genders. The rate of vaccination was higher among elderly participants who reported having a lower level of education (table 1).

Table 2 summarises the influenza vaccination coverage rate among older people for season 2010/2011. After bivariate analysis, we found that older residents in rural 


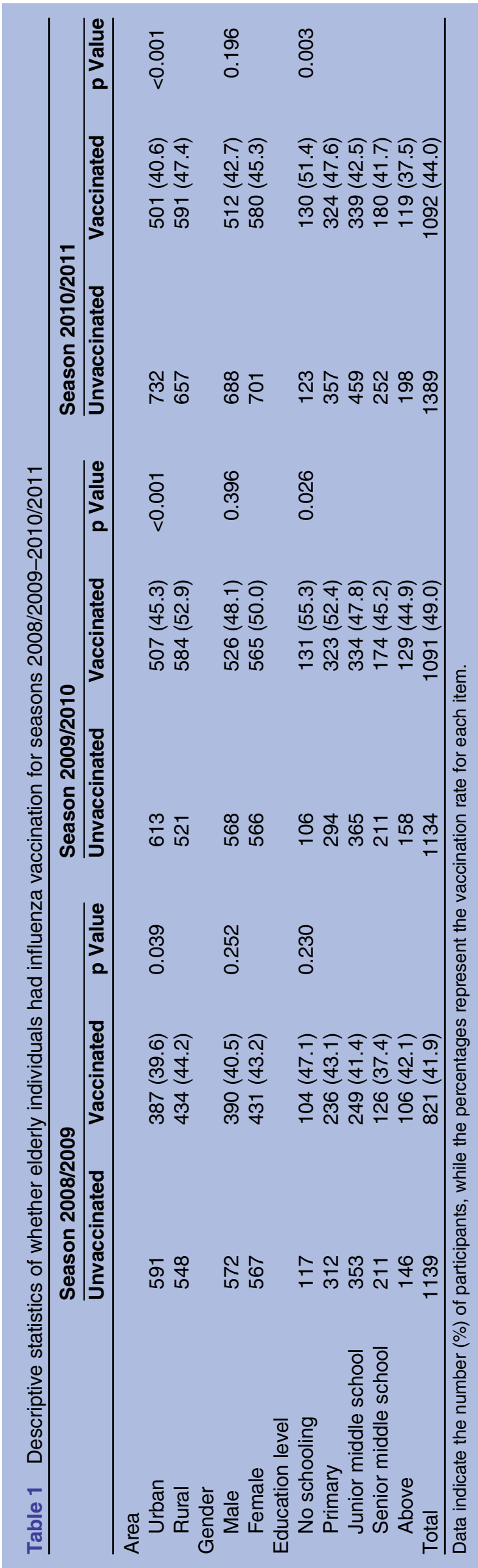

areas have a higher probability of receiving influenza vaccination than residents in urban areas. In addition, lower education level (no schooling or primary school), perceived self-condition as 'bad', self-reported regular engagement in exercise and good level of knowledge about the disease (ie, awareness of the symptoms and peak of disease) and the importance of the vaccine as a preventive measure (comparing with ventilation, exercise and traditional Chinese medicine) were factors associated with a higher influenza vaccination rate.

The results of the multivariate analysis are shown in table 3 . The variables that were significantly associated with a higher likelihood of being vaccinated were lower education level, self-reported 'bad' health status/condition, self-reported regular engagement in exercise and the importance of the vaccine as a preventive measure. Knowledge regarding the seasonal peaks of influenza was not associated with vaccine receipt in the multivariate model.

\section{DISCUSSION}

In this study, self-reported vaccination coverage was found to be $44 \%$ in the first postpandemic season (2010/2011), with no differences in receipt between genders. In comparison to the coverage rates reported previously for other countries, the figures documented for our participants were lower. ${ }^{5-7}$ While it should be noted that the periods of reporting are different for each of these studies, it is important to compare the levels of success among the different campaigns. Despite a widespread influenza vaccination programme in Beijing, the vaccine coverage was poor and did not meet the WHO desired target of $75 \%$ in $2010 .{ }^{11}$

In Beijing, there is a government policy to administer the influenza vaccine free of charge to all vulnerable populations including school-aged children and older people aged $\geq 60$ years via public health centres. Therefore, in the rural areas, even the elderly people with lower income will get benefit from the government policy. We found that the vaccination rate among older people was lower in urban areas than in rural areas. Better compliance among the rural population may account for this situation. This finding was not in line with the earlier study undertaken in other city in China, which found that farmers had less compliance with preventive behaviours. ${ }^{12}$

In this study, we found that lower educational level, perceived 'bad' health status, frequency of exercise and basic knowledge about influenza and vaccination were associated with vaccine receipt. With regard to the level of education, our finding is not in accord with previous studies that have identified a connection between the level of education and influenza vaccine receipt. Link et al found that having at least a high school education was positively correlated with influenza vaccine receipt. ${ }^{13}$ Similar results were also reported in an earlier study by Andrew $e t a l^{7}$ who found that people who were not 
Table 2 Potential factors associated with influenza vaccination among the elderly people in a univariate analysis

\begin{tabular}{|c|c|c|c|c|}
\hline & Unvaccinated & Vaccinated & p Value & OR $(95 \% \mathrm{Cl})$ \\
\hline \multicolumn{5}{|l|}{ Area } \\
\hline Urban & $501(45.9)$ & $732(52.7)$ & Reference & \\
\hline Rural & $591(54.1)$ & 657 (47.3) & 0.001 & $1.314(1.121$ to 1.541$)$ \\
\hline Education level & & & 0.003 & \\
\hline No schooling & $130(11.9)$ & $123(8.9)$ & Reference & \\
\hline Primary & $324(29.7)$ & 357 (25.7) & 0.301 & 0.859 (0.643 to 1.146$)$ \\
\hline Junior middle school & $339(31.0)$ & 459 (33.0) & 0.013 & 0.699 (0.526 to 0.928$)$ \\
\hline Senior middle school & $180(16.5)$ & $252(18.1)$ & 0.014 & 0.676 (0.495 to 0.923$)$ \\
\hline Above & 119 (10.9) & $198(14.3)$ & 0.001 & 0.569 (0.407 to 0.795$)$ \\
\hline Perceived self-condition & & & 0.014 & \\
\hline Bad & $170(12.2)$ & $169(15.5)$ & Reference & \\
\hline Common & $688(49.5)$ & $556(50.9)$ & 0.091 & 0.813 (0.639 to 1.034$)$ \\
\hline Good & 531 (38.2) & 367 (33.6) & 0.005 & 0.695 (0.541 to 0.894$)$ \\
\hline \multicolumn{5}{|l|}{ Taking exercises } \\
\hline Rarely & $654(47.1)$ & $422(38.6)$ & Reference & \\
\hline Regularly & 735 (52.9) & $670(61.4)$ & $<0.001$ & $1.413(1.203$ to 1.660$)$ \\
\hline \multicolumn{5}{|l|}{ Having ILI during the past year } \\
\hline Yes & $636(45.8)$ & $512(46.9)$ & Reference & \\
\hline No & $753(54.2)$ & $580(53.1)$ & 0.586 & 0.957 (0.816 to 1.122$)$ \\
\hline \multicolumn{5}{|l|}{ Best measure for preventing influenza } \\
\hline Vaccine & $520(37.4)$ & $629(57.6)$ & Reference & \\
\hline $\begin{array}{l}\text { Other methods (ventilation, exercise, } \\
\text { and traditional Chinese medicine) }\end{array}$ & $869(62.6)$ & $463(42.4)$ & $<0.001$ & $0.440(0.375$ to 0.518$)$ \\
\hline \multicolumn{5}{|l|}{ Aware of peak season of influenza } \\
\hline Yes & $1210(87.1)$ & $988(90.5)$ & Reference & \\
\hline No & $179(12.9)$ & $104(9.5)$ & 0.009 & 0.712 (0.551 to 0.919$)$ \\
\hline \multicolumn{5}{|l|}{ Aware of the symptom of influenza } \\
\hline Yes & 709 (51.0) & $625(57.2)$ & Reference & \\
\hline No & $680(49.0)$ & 467 (42.8) & 0.002 & $0.779(0.664$ to 0.914$)$ \\
\hline
\end{tabular}

vaccinated tended to have a lower level of education. As our findings were in contrast to these studies, it is possible that many knowledgeable elderly persons may worry about the side effect of the influenza vaccine, ${ }^{10}$ which may lead to the lower vaccination rate among older people with a higher educational level.

In our survey, participants who reported their health condition as being 'bad' were more likely to receive the influenza vaccine, compared with those who reported an underlying chronic disease or immunological disorder. These results are in line with earlier studies that have also demonstrated that chronically ill persons are more likely to receive a seasonal influenza vaccination. ${ }^{14} 15$ This might due to the awareness of the increasing risk of catching influenza as one has chronic disease. ${ }^{14}$ In addition, as found in an earlier study, chronically ill persons followed the recommendations by health authorities better than people without a chronic illness, while some healthy people who may have believed influenza to be a minor disease usually underestimated its impact. ${ }^{15}$

We found that participants who believed that the vaccine was the most effective method of preventing influenza were most likely to be vaccinated. Additionally, being knowledgeable about influenza (ie, knowing what the symptoms are and when the peak of the disease occurs each year) was also associated with vaccine uptake. Interestingly, there was no association found between vaccine receipt and having influenza-like-illness. Education campaigns should continue to focus on increasing the awareness levels about influenza, highlighting the possible complications associated with the virus (especially for those with underlying health conditions), as well as promote the need for the vaccine among the elderly.

In the pandemic season $(2009 / 2010)$, vaccination of elderly residents aged 60 years and older in Beijing against pandemic (H1N1) influenza was prioritised. The vaccine was provided free of charge and was distributed via community hospitals. As highlighted in the results, vaccine uptake peaked during this period at $49 \%$. However, the reported uptake of the influenza vaccine was still much lower than that of other industrialised countries such as Korea $(81.7 \%)^{16}$ and France $(62.6 \%) .{ }^{17}$ We assume that the increase in the vaccine uptake for season $2009 / 2010$ is associated with the government's pandemic influenza education campaign; 
Table 3 Independent factors associated with influenza vaccination among elderly individuals in a multivariate analysis

\begin{tabular}{|c|c|c|}
\hline & p Value & OR $(95 \% \mathrm{CI})$ \\
\hline Education level & \multicolumn{2}{|l|}{0.001} \\
\hline No schooling & \multicolumn{2}{|l|}{ Reference } \\
\hline Primary & 0.229 & $0.832(0.616$ to 1.123$)$ \\
\hline Junior middle school & 0.003 & 0.641 (0.476 to 0.864$)$ \\
\hline Senior middle school & 0.010 & $0.648(0.466$ to 0.899$)$ \\
\hline Above & 0.001 & $0.535(0.375$ to 0.763$)$ \\
\hline $\begin{array}{l}\text { Perceived } \\
\text { self-condition }\end{array}$ & \multicolumn{2}{|l|}{0.014} \\
\hline Bad & \multicolumn{2}{|l|}{ Reference } \\
\hline Common & 0.256 & $0.864(0.672$ to 1.111$)$ \\
\hline Good & 0.009 & $0.703(0.540$ to 0.915$)$ \\
\hline \multicolumn{3}{|l|}{ Taking exercises } \\
\hline Rarely & \multicolumn{2}{|l|}{ Reference } \\
\hline Regularly & $<0.001$ & 1.475 (1.246 to 1.745$)$ \\
\hline \multicolumn{3}{|c|}{ Best measure for preventing influenza } \\
\hline Vaccine & \multicolumn{2}{|l|}{ Reference } \\
\hline $\begin{array}{l}\text { Other methods } \\
\text { (ventilation, exercise } \\
\text { and traditional } \\
\text { Chinese medicine) }\end{array}$ & $<0.001$ & $0.450(0.381$ to 0.531$)$ \\
\hline
\end{tabular}

Those variables with $p<0.05$ in bivariate analysis, overall seven variables, were included in multivariate logistic regression analysis. Backward logistic regression was conducted by removing variables with $p>0.10$, and five variables, as shown in the table, were left in the final regression model. Matched ORs and $95 \% \mathrm{Cls}$ were calculated. All statistical tests were two-sided, and significance was defined as $p<0.05$. The statistic for each variable was obtained after adjustment for the other four variables in the final regression model.

however, we were unable to differentiate what proportion of the sample received the seasonal influenza vaccine versus the pandemic-specific vaccine. After the 2009/2010 pandemic season, there was a decline in the influenza vaccination coverage among our participants. The decreased coverage figure after the 2009 pandemic is in line with the findings of a survey which examined the uptake of seasonal influenza vaccine in Germany. The authors reported that influenza vaccine uptake among older people in Germany has decreased in the postpandemic season 2010/2011, not only in comparison to season $2008 / 2009$ but also to the pandemic season $2009 / 2010 .^{18}$ In comparison, a study from the UK showed that the coverage figures for the influenza vaccine remained stable between seasons 2009/2010 and $2010 / 2011$ among persons aged $\geq 65$ years, ${ }^{19}$ while in France an increase in seasonal influenza vaccine uptake was observed in the postpandemic season among persons aged $\geq 65$ years with underlying chronic conditions $\left(62.6 \%\right.$ in season $2009 / 2010^{17}$ vs $71.0 \%$ in season $\left.2010 / 2011^{20}\right)$. As discussed by Merle et al, the uptake of seasonal influenza vaccines should be carefully monitored in the target group to identify if the downtrend of the influenza vaccination coverage still continues. ${ }^{18}$

There are a number of limitations to this study. First, as this study was based on self-reported data, it has certain weaknesses that may serve as sources of bias in data interpretation, that is, vaccine receipt, participating in exercise $>30 \mathrm{~min} /$ day. While we used a stratified sampling approach in the study, the final sample may not be representative of all residents aged $\geq 60$ years in Beijing. Participants were asked about their vaccine history over a 3-year period, which probably would have resulted in recall bias, and vaccination status was not verified. Finally, the questionnaire used in this investigation may have been inadequate for evaluating other factors that may have had a substantial influence on vaccine coverage rates (eg, religious beliefs, socioeconomic factors, etc).

In conclusion, influenza vaccine coverage in Beijing still remains suboptimal. Further work needs to be undertaken to ascertain whether the method of distributing the vaccine is adequate and whether health professionals are appropriately promoting the vaccine. Finally, education efforts should continue to highlight the need for the vaccine among individuals who are at risk from the disease and its associated complications.

Contributors $Y Z$ designed the study, directed the implementation of the study and performed the statistical analysis. PY helped conduct the literature review. SW and CM collected the data and helped set up the database. HS helped design the analytic strategy and performed some statistical analysis. CRM and QW designed the study. All the authors approved the final version of the manuscript for submission.

Funding This work was supported by the Beijing Municipal Science and Technology Commission (Z131100005613048), National Key Program for Infectious Disease of China (2012ZX10004215-003-001) and China Special Grant for the Prevention and Control of Infectious Diseases (2013ZX10004218). The funders did not influence or participate in the design and conduct of the study, in the collection, management, analysis or interpretation of the data, in the writing of the manuscript or in the decision to submit the article for publication. The researchers were independent of the funders. The corresponding author had full access to all of the data in the study and had final responsibility for the decision to submit the article for publication.

Competing interests CRM has received funding from influenza vaccine manufacturers GSK and CSL Biotherapies for investigator-driven research. HS holds an NHMRC Australian-based Public Health Training Fellowship (1 012 631) and has received funding for investigator-driven research/ invitations to present from GSK, CSL and Sanofi-Pasteur.

\section{Patient consent Obtained.}

Ethics approval Ethical approval was obtained from the institutional review board and human research ethics committee of the Beijing Center for Disease Prevention and Control.

Provenance and peer review Not commissioned; externally peer reviewed. Data sharing statement No additional data are available.

Open Access This is an Open Access article distributed in accordance with the Creative Commons Attribution Non Commercial (CC BY-NC 3.0) license, which permits others to distribute, remix, adapt, build upon this work noncommercially, and license their derivative works on different terms, provided the original work is properly cited and the use is non-commercial. See: http:// creativecommons.org/licenses/by-nc/3.0/

\section{REFERENCES}

1. Monto AS. Seasonal influenza and vaccination coverage. Vaccine 2010;28(Suppl 4):D33-44.

2. Gil A, Gil R, Oyaguez I, et al. Hospitalization by pneumonia and influenza in the 50-64 year old population in Spain (1999-2002). Hum Vaccin 2006;2:181-4. 
3. He J, Gu D, Wu X, et al. Major causes of death among men and women in China. N Engl J Med 2005;353:1124-34.

4. Zhang $\mathrm{Y}$, Seale $\mathrm{H}$, Yang $\mathrm{P}$, et al. Factors associated with the transmission of pandemic (H1N1) 2009 among hospital healthcare workers in Beijing, China. Influenza Other Respi Viruses 2013;7:466-71.

5. Takayama M, Wetmore CM, Mokdad AH. Characteristics associated with the uptake of influenza vaccination among adults in the United States. Prev Med 2012;54:358-62.

6. Mereckiene J, Cotter S, Nicoll A, et al. National seasonal influenza vaccination survey in Europe, 2008. Euro Surveill 2008;13. pii: 19017.

7. Andrew MK, McNeil S, Merry $\mathrm{H}$, et al. Rates of influenza vaccination in older adults and factors associated with vaccine use: a secondary analysis of the Canadian Study of Health and Aging. BMC Public Health 2004:4:36.

8. Lau JT, Yang X, Tsui HY, et al. Prevalence of influenza vaccination and associated factors among community-dwelling Hong Kong residents of age 65 or above. Vaccine 2006;24:5526-34.

9. Nowalk MP, Zimmerman RK, Shen S, et al. Barriers to pneumococcal and influenza vaccination in older communitydwelling adults (2000-2001). J Am Geriatr Soc 2004;52:25-30.

10. Kwong EW, Lam IO, Chan TM. What factors affect influenza vaccine uptake among community-dwelling older Chinese people in Hong Kong general outpatient clinics? J Clin Nurs 2009;18:960-71.

11. Kwong EW, Pang SM, Choi P, et al. Influenza vaccine preference and uptake among older people in nine countries. J Adv Nurs 2010;66:2297-308.

12. Lin $Y$, Huang L, Nie S, et al. Knowledge, attitudes and practices (KAP) related to the pandemic (H1N1) 2009 among Chinese general population: a telephone survey. BMC Infect Dis 2011;11:128.
13. Link MW, Ahluwalia IB, Euler GL, et al. Racial and ethnic disparities in influenza vaccination coverage among adults during the 20042005 season. Am J Epidemiol 2006;163:571-8.

14. Mok E, Yeung SH, Chan MF. Prevalence of influenza vaccination and correlates of intention to be vaccinated among Hong Kong Chinese. Public Health Nurs 2006;23:506-15.

15. Gaygisiz U, Gaygisiz E, Ozkan T, et al. Why were Turks unwilling to accept the $A / H 1 N 1$ influenza-pandemic vaccination? People's beliefs and perceptions about the swine flu outbreak and vaccine in the later stage of the epidemic. Vaccine 2010;29: 329-33.

16. Ryu SY, Kim SH, Park $\mathrm{H}$, et al. Influenza vaccination among adults 65 years or older: a 2009-2010 community health survey in the Honam region of Korea. Int $J$ Environ Res Public Health 2011:8:4197-206.

17. Vaux S, Van Cauteren D, Guthmann JP, et al. Influenza vaccination coverage against seasonal and pandemic influenza and their determinants in France: a cross-sectional survey. BMC Public Health 2011;11:30

18. Bohmer MM, Walter D, Falkenhorst G, et al. Barriers to pandemic influenza vaccination and uptake of seasonal influenza vaccine in the post-pandemic season in Germany. BMC Public Health 2012;12:938.

19. Health Protection Agency: influenza vaccinaton uptake monitoring on behalf of the Department of Health. http://www.hpa.org.uk/web/ HPAweb\&HPAwebStandard/HPAweb_C/1195733756886\#r5 (accessed 2011).

20. Guthmann JP, Fonteneau L, Bonmarin I, et al. Influenza vaccination coverage one year after the $A(\mathrm{H} 1 \mathrm{~N} 1)$ influenza pandemic, France, 2010-2011. Vaccine 2012;30:995-7. 